\title{
A Prospective Observational Study: Phenytoin Pharmacokinetic Pattern in Cerebrovascular Accident and Head Trauma Patients in Warangal Population
}

\author{
Yashwanth Kumar $K^{1}$, Manasa Sowmya $K^{2}$, Gireesh Kumar $\mathbf{M}^{3 *}$,Venkateshwarlu $E^{1}$, \\ Sharavana bhava B.S ${ }^{1}$ \\ ${ }^{1}$ Department of Clinical Pharmacy \& Pharm. D., Vaagdevi College of Pharmacy, Kakatiya University, Warangal-506007, Telangana, India. \\ ${ }_{2}^{2}$ Manisha Neuropsychiatry Clinic, Kakaji Colony, Hanamkonda, Warangal-506007, Telangana, India. \\ ${ }^{3}$ Department of Psychiatry, Kakatiya medical College, Warangal-506007, Telangana, India.
}

\begin{tabular}{l} 
A R T I C L E I N F O \\
\hline Article history: \\
Received 11 Jan 2019 \\
Received in revised form 16 Jan 2019 \\
Accepted 18 Jan 2019 \\
doi.org/10.38111/ijapb.20190501003 \\
Keywords: \\
Head injury; Pharmacokinetics; \\
Phenytoin; Cerebrovascular accident; \\
Head trauma. \\
\hline
\end{tabular}

\begin{abstract}
A B S T RAC T
An phenytoin is commonly administered as prophylactic or treatment of epileptic episodes in acute brain injury due to head injury. The aim of the study is to evaluate PK pattern of phenytoin in patients with traumatic and non-traumatic brain injuries. This study was carried out in 30 adult head injury patients and who were administered with phenytoin for prophylaxis of post trauma seizures or treatment. Serum Phenytoin concentrations (Cp) were determined and were compared between CVA and HT patients. The Km and Vmax were significantly higher in HT patients. The $\mathrm{Cp}$ and the $\mathrm{Cp} /$ dose ratio were higher in the CVA patients significantly $(\mathrm{P}<0.05)$. APACHE $\Pi$ score was significantly lower than the baseline at the end of the study in each group of patients $(\mathrm{P}<0.05)$. Due to significant differences in $\mathrm{Cp}$ and PK parameters between HT and CVA patients, close attention must be paid to the PK behavior of phenytoin in the efforts to improve the patient's outcome after a severe HT.
\end{abstract}

\section{Introduction}

Head injury is a trauma to the scalp, skull or brain which is one of the leading causes of morbidity and mortality around the globe [1]. Head injury may lead to bleeding in the brain tissues and in certain layers that surround the brain (subarachnoid haemorrhage, subdural haemorrhage and extradural haemorrhage). Head injury is one of the most common reasons for an emergency visit to the hospital. Traumatic brain injury (TBI) accounts for over 1 in 6 injury-related admissions each year [2]. Traumatic brain injury is a leading cause of morbidity, mortality, disability, in India and other developing countries. Road traffic injuries are leading cause $(60 \%)$ of traumatic brain injury followed by falls (20-25\%), violence and alcohol involvement (15- 20\%) in India [3]. Head injuries are commonly caused by a blow to the head that are usually associated with vehicle accidents, falls, and sports related accidents.The treatment of the condition depends on the seriousness of the injury. Mild traumatic brain injures requires over-the-counter pain relievers to treat headache and usually needs to be monitored closely at home for any persistent, exacerbating or new symptoms. Moderate to severe brain injuries concentrate on enough oxygen, sufficient blood supply, blood pressure and avoid any further injury to the head. Treatment limitations for peripheral destruction of the brain immediately after an injury may contain: Diuretics, Anti-seizure drugs and Coma-inducing drugs. Urgent surgery is needed to reduce further damage to the brain. Surgery may be used for the following issues: Eliminate clotted blood (hematoma), repairing skull fractures, bleeding in the brain, and opening in the skull [4].

In the beginning stage after a mind injury, seizure may cause auxiliary cerebrum harm because of expanded metabolic requests, expanded intracranial weight, and abundance synapse discharge. It has been shown that seizures are a significant reason for dismalness.

Phenytoin has been normally utilized as an anticonvulsant specialist for the treatment of or the prophylaxis against seizures for quite a long time. Despite the fact that the confusions of early seizure are the 
essential remedial sound for the utilization of phenytoin, its neuroprotective impact is the other main consideration might be intervened by a voltage-subordinate bar of sodium channels $[5,6]$. Phenytoin is $90 \%$ bound to albumin and $95 \%$ processed by the liver. The hepatic freedom of phenytoin essentially relies upon the unbound medication portion and the movement of hepatic medication processing compounds [7]. After an extreme head injury, a few pharmacokinetic changes happen. These are blood-brain barrier disturbance and changes in medication entrance, cytokine discharge, which can influence the cytochrome P450 chemical framework, modification in protein official and medication transportation, and hypothermia? Albeit a few examinations have demonstrated critical digestion changes in patients after a serious head injury, scarcely any investigations have zeroed in on the impacts of neurotrauma on medication digestion. The comprehension of conceivable pharmacokinetic adjustments is significant for the protected and viable medication use in this patient subset. Hence, we focused on the difference between traumatic and nontraumatic brain injury (TBI) in total phenytoin serum concentration to gain a better understanding of phenytoin pharmacokinetic behavior in two subgroups of patients [8$10]$.

\section{Material and Methods}

This was a prospective, observational study conducted at the Intensive Care Unit (ICU) of Neurosurgery department MGM Hospital, Warangal. Thirty adult brain injury patients who were admitted to the ICU and required phenytoin for the treatment or the prophylaxis of postinjury seizures were included in this study. Patients aged 18 or above, with moderate to severe acute (traumatic or nontraumatic) brain injury who had the Glasgow Coma Scale (GCS) score <13, requiring intravenous phenytoin were chosen. Exclusion criteria:, second or third degree heart block, bradycardia, lactating mothers, hypotension, pregnancy, preexisting hepatic or renal disease, a history of phenytoin administration (during current hospitalization), hypersensitivity to phenytoin, and/or concomitant drug therapy with cimetidine, chloramphenicol, phenobarbital, carbamazepine, valproate, theophylline, erythromycin, isoniazid, trimethoprim, sulfonamides, salicylates, or warfarin, which can affect the pharmacokinetic behavior of phenytoin.

Based on the type of brain injury, the patients were divided into two groups: the cerebrovascular accident (CVA) group and the head trauma (HT) group.

All the patients received an intravenous loading dose of $15 \mathrm{mg} / \mathrm{kg}$ phenytoin sodium through an infusion pump at a maximum rate of 50 $\mathrm{mg} / \mathrm{min}$, followed by a maintenance dose of $6 \mathrm{mg} / \mathrm{kg} /$ day divided into three equal doses, administered at intervals of $8 \mathrm{~h}$ for 3 days. Afterwards, the maintenance dose was reduced to $4.5 \mathrm{mg} / \mathrm{kg} /$ day and continued. This is the most popular dosing regimen when the drug is used locally. For all the patients, there were three scheduled time points for the phenytoin dose through concentration determination. The first blood sample was taken 30 min before initiating a new maintenance dose $(4.5 \mathrm{mg} / \mathrm{kg} /$ day $)$. The second and third blood samples were obtained 2 and 4 days after the first sample was taken, respectively. All samples were taken $30 \mathrm{~min}$ before the next dose.

The Acute Physiology and Chronic Health Evaluation П (APACHE П) scoring system wąs used to grade the disease severity. The APACHE $\Pi$ score and GCS were calculated for each patient separately at the baseline and each sampling time.

The electrocardiogram was continuously monitored with lead II, systolic, diastolic, mean arterial pressure, heart rate, and central venous pressure in accordance with the ICU protocol. Paraclinical parameters, such as arterial blood gas, serum electrolytes, serum creatinine, blood urea nitrogen, bilirubin, glucose, and complete blood count were measured during the study period. Serum albumin concentrations were measured at the baseline and sampling days.

The blood samples were allowed to clot and centrifuged at room temperature for $15 \mathrm{~min}$ at $3000 \mathrm{rpm}$. The serum was aspirated and frozen at $-30^{\circ} \mathrm{C}$ until it was analyzed. Phenytoin plasma concentrations were quantified by high performance liquid chromatography technique with method of Cwik et al [11].

The Michaelis-Menten pharmacokinetic model (equation 1) was used to calculate the maximum rate of metabolism (Vmax) and the Michaelis-Menten elimination rate constant (Km).

$$
\text { (S) (F) }(\text { Dose } / \mathrm{t})=\mathrm{Vmax} \times \mathrm{Cp} / \mathrm{Km}+\mathrm{Cp}(1)
$$

Where $\mathrm{Cp}(\mathrm{mg} / \mathrm{L})$ is the $\mathrm{Cp}$, Vmax (mg/day) is the maximum rate of metabolism, $\mathrm{Km}(\mathrm{mg} / \mathrm{L})$ is the concentration at which metabolism rate is half the maximum rate, $\mathrm{F}=1$ is phenytoin bioavailability, $\mathrm{S}=0.92$ shows sodium salt factor, and dose/t (mg/day) is daily dose of phenytoin.

The Winter-Tozer method (equation 2) was used to calculate the adjusted total serum $\mathrm{Cp}$ based on the serum albumin concentration (Alb). The adjusted total serum Cp were used to calculate the Vmax and the $\mathrm{Km}$.

$$
\mathrm{Cp}=\text { Cmeasured } /[(0.9 \times \mathrm{Alb} / 4.4)+0.1](2)
$$

Where $\mathrm{Cp}(\mathrm{mg} / \mathrm{mL})$ is $\mathrm{Cp}$ that would be observed if patient had normal protein binding, Cmeasured $(\mathrm{mg} / \mathrm{mL})$ is $\mathrm{Cp}$ measured by laboratory, and $\mathrm{Alb}(\mathrm{g} / \mathrm{dL})$ is patient's serum albumin concentration.

Statistical analysis was performed using Statistical Package for the Social Sciences software version 22 for windows (SPSS Inc., IBM Co., Chicago, IL, USA). A nonparametric method (Wilcoxon signed-rank test) was used to compare the pharmacokinetic parameters, APACHE II, the GCS scores, and the albumin serum concentrations at the baseline and the sampling days. These data were compared between the two groups of patients (traumatic and nontraumatic) using the Mann-Whitney test. The results were expressed as the mean \pm standard deviation (SD) The Spearman rank test was used for the evaluation of correlation between Vmax, Km, Cp, Cp/Dose ratio, and APACHE II scores at the time of sampling. $P<0.05$ was considered statistically significant.

\section{Results}

A total of thirty patients with moderate to severe acute brain injury in ICU (15 CVA and 15 HT) were enrolled in the study. The demographic and clinical data of the patients is given in Table 1. Table 2 explains about the mean values $( \pm \mathrm{SD}$ ) of the adjusted phenytoin serum concentration at different time schedules and pharmacokinetic 
parameters (Vmax and $\mathrm{Km}$ ). The phenytoin serum concentration per dose ratios ( $\mathrm{Cp} /$ Dose ratio) explained in Table 2 shows the total $\mathrm{Cp}$ in all thirty patients.

Table 1: Patients 'characteristics

\begin{tabular}{|c|c|c|c|}
\hline Characteristics & CVA group & HT group & $P$ \\
\hline Weight(kg) & $63.4 \pm 5.5$ & $60.21 \pm 6.25$ & 0.310 \\
\hline Age (year) & $51 \pm 7.9$ & $42.72 \pm 15.4$ & 0.232 \\
\hline GCS & $8.2 \pm 2.5$ & $6.5 \pm 24.41$ & 0.218 \\
\hline APACHE-II score & $16.3 \pm 3.4$ & $18.05 \pm 4.92$ & 0.576 \\
\hline Serum albumin & $3.8 \pm 0.14$ & $3.02 \pm 0.15$ & 0.693 \\
\hline
\end{tabular}

\begin{tabular}{|c|c|c|c|}
\hline $\begin{array}{c}\text { Number of } \\
\text { patients }\end{array}$ & $\begin{array}{c}\mathrm{Cp1} \\
(\mathrm{mcg} / \mathrm{mL})\end{array}$ & $\begin{array}{c}\mathrm{Cp} 2 \\
(\mathrm{mcg} / \mathrm{mL})\end{array}$ & $\begin{array}{c}\mathrm{Cp3} \\
(\mathrm{mcg} / \mathrm{mL})\end{array}$ \\
\hline \multicolumn{4}{|c|}{ Patients with CVA } \\
\hline 1 & 11.98 & 5.20 & 5.35 \\
\hline 2 & 18.90 & 7.98 & 8.96 \\
\hline 3 & 24.74 & 8.56 & 9.04 \\
\hline 4 & 22.56 & 9.99 & 9.54 \\
\hline 5 & 17.36 & 3.95 & 4.98 \\
\hline 6 & 11.91 & 4.80 & 5.99 \\
\hline 7 & 11.90 & 5.08 & 4.86 \\
\hline 8 & 15.67 & 5.91 & 6.94 \\
\hline 9 & 16.93 & 6.84 & 6.66 \\
\hline 10 & 16.59 & 6.55 & 6.93 \\
\hline 11 & 15.08 & 6.98 & 5.56 \\
\hline 12 & 20.56 & 5.07 & 4.09 \\
\hline 13 & 19.80 & 6.11 & 6.07 \\
\hline 14 & 17.55 & 7.05 & 7.95 \\
\hline 15 & 13.21 & 6.65 & 5.88 \\
\hline \multicolumn{4}{|c|}{ Patients with HT } \\
\hline 16 & 11.92 & 5,92 & 5.96 \\
\hline 17 & 9.89 & 5.99 & 6.09 \\
\hline 18 & 11.60 & 6.29 & 5.75 \\
\hline 19 & 7.40 & 5.31 & 4.90 \\
\hline 20 & 9.62 & 6.92 & 5.83 \\
\hline 21 & 9.96 & 5.90 & 5.67 \\
\hline 22 & 8.90 & 3.88 & 4.82 \\
\hline 23 & 9.99 & 5.76 & 5.77 \\
\hline 24 & 10.81 & 4.98 & 4.99 \\
\hline 25 & 7.92 & 5.55 & 6.00 \\
\hline 26 & 10.78 & 4.78 & 5.07 \\
\hline 27 & 11.70 & 5.93 & 6.01 \\
\hline 28 & 9.74 & 6.10 & 5.86 \\
\hline 29 & 8.44 & 6.92 & 4.77 \\
\hline 30 & 10.04 & 5.82 & 5.41 \\
\hline
\end{tabular}

Table 3: Vmax, Km and Phenytoin serum concentration per dose in CVA \& HT Patients

\begin{tabular}{ccc}
\hline Particulars & CVA & HT \\
\hline Vmax (mg/kg/day) & $6.9 \pm 2.5$ & $8.3 \pm 2.9$ \\
Km (mg/L) & $3.8 \pm 1.6$ & $5.2 \pm 2.1$ \\
Ratio 1 & $2.8 \pm 1.20$ & $1.7 \pm 0.98$ \\
Ratio2 & $1.5 \pm 0.78$ & $1.3 \pm 0.73$ \\
Ratio3 & $1.4 \pm 0.61$ & $1.2 \pm 0.65$ \\
\hline Phenytoin serum concentration per dose in CVA and HT patients. Vmax and Km in head \\
trauma (HT) and cerebrovascular accident patients (CVA). Data are presented as \\
mean \pm standard deviation; CVA=Cerebrovascular accident, HT=Head trauma, \\
Vmax=Maximum rate of drug metabolism, Km=Concentration at which the rate of drug \\
metabolism is 50\% of Vmax. *Difference with HT patients was significant $(P<0.05)$. \\
**Difference with HT patients was statistically significant $(P<0.05)$ \\
\hline
\end{tabular}

The evaluation of serum phenytoin concentrations ( $\mathrm{Cp}$ ) at different time points showed that the difference between Vmax and $\mathrm{Km}$ in the both group of patients (CVA and HT) was significant $(\mathrm{P}<0.05)$ and were significantly higher in HT patients than the CVA group. The Cp and the $\mathrm{Cp} /$ Dose ratio were significantly higher in the CVA group patients during the first stage $(\mathrm{P}<0.05)$. The difference between the $\mathrm{Cp}$ and the $\mathrm{Cp} /$ Dose ratio in the both group of patients (CVA and HT) was not significant during second and third stages. Plasma phenytoin concentration did not differ significantly in patients with severe TBI in comparison with patients with moderate TBI while there was no significant difference between the CVA and the HT groups for APACHE II scores at the baseline and the sampling days, a decreasing trend was observed for these scores. The APACHE П score was significantly lower than the baseline at the end of the study in each group of patients $(\mathrm{P}<0.05)$. In addition, no significant correlation was observed between Vmax, $\mathrm{Km}, \mathrm{Cp}, \mathrm{Cp} /$ Dose ratio, and APACHE II scores at the time of sampling.

\section{Discussion}

Our research work results are in compliance with various works in this area. Alteration in phenytoin protein binding in pediatric patients with acute head injury was studied by Griebel et al., 1990. They contrasted kids and HT with epileptic patients accepting constant phenytoin treatment. They saw that in spite of a decrease in the all out Cp over the 10-day study period, the free part of phenytoin in the injury patients expanded [12].

Boucher et al., 1987 noticed an expanded free part of phenytoin between days 1 and 7 of every the vast majority of injury patients. During the subsequent period, three out of four patients had significantly lower absolute plasma focuses than the anticipated qualities. They clarified the outcome by expanded digestion and diminished protein authoritative, which can diminish the absolute $\mathrm{Cp}$ [13].

In an ensuing report, the same group picked up similar outcomes. The urinary metabolite discharge data were predictable with an enhancement in the systemic clearance of phenytoin, which can be trailed by a reduction in the absolute $\mathrm{Cp}$ [14].

Markowsky et al., 1996 noticed that during the acute stage, there was a pattern of diminishing serum concentrations. They inferred that the true steady state serum concentrations may not occur [15].

In one investigation, led by Bauer et al., $1983 \mathrm{Cp}$ in HT patients was contrasted and epileptic patients. They demonstrated that however the patients with HT had factually lower and sub therapeutic total $\mathrm{Cp}$, the free concentrations were comparative and therapeutic contrasted and those fixations in grown-up epileptic patients. It was proposed that a higher level of unbound phenytoin was the consequence of hypoalbuminemia in the HT patients. In spite of a greater clearance of total phenytoin in HT patients, the clearance of the unbound drug was similar between the two groups [16].

Although the second and third total $\mathrm{Cp}$ were sub therapeutic $(<10$ $\mu \mathrm{g} / \mathrm{ml}$ ), we did not measure free $\mathrm{Cp}$ because serum albumin concentrations in all the samples were within the normal range. Hence, it is unlikely that the changes in protein binding are entirely responsible for the dramatic increase in dosage requirement in this population. Moreover, a better in vivo-in vitro correlation can be attained by applying a total concentration versus an unbound fraction 
for some drugs metabolized in human hepatocytes and microsoms. Srisaeng et al. evaluated pharmacokinetics of phenytoin in 122 patients with early TBI and showed that values of Vm in TBI patients are slightly higher. They concluded that the slightly higher value of $\mathrm{Vm}$ was associated with increased metabolism rate of phenytoin during early phase of acute brain injury [8].

Sadeghi et al., 2013 demonstrated the lack of correlation between total and free concentration of phenytoin in TBI patients. They finished up free part of medication should be monitored alongside total concentration in this populace to forestall both toxicity and treatment failure [17].

Therefore, due to significant differences in phenytoin plasma concentration and pharmacokinetic parameters between CVA and HT patients, close monitoring must be done to the pharmacokinetic behavior of phenytoin in the efforts to improve a patient's outcome after a severe HT. Although the exact mechanism of decreased plasma concentration of phenytoin in HT patients is unclear, it is hypothesized that an increase in hepatic metabolism and unbound plasma concentration may involve in this phenomenon $[8,13,18]$. The previous studies demonstrated that the clearance of drugs may also be increased as a consequence of potential drug-drug interaction, high daily intake of protein (by increase in oxidative drug metabolism), fluid shifts, or pH changes after severe brain injury $[18,19]$.

\section{Conclusion}

The exact mechanism of an increased clearance of phenytoin in patients with Head injuries is unknown, it is clear that they require doses higher than the recommended to obtain therapeutic plasma concentrations. A close monitoring of the total $\mathrm{Cp}$ is substantial to individualize the dose. Additional investigations and examinations are expected to additionally clarify the components liable for the noticed changes in $\mathrm{Cp}$ and to portray the time course of these changes.

Sound knowledge about primary immune deficiencies should be present among health care practitioners for differential diagnosis of chronic granulomatous disease and application of test at proper time would help in timely diagnosis of disease.

\section{Acknowledgements}

Authors are thankful to the Principal and Secretary, Vaagdevi college of Pharmacy, for providing necessary facilities and actions towards the fruitful completion of this research work.

\section{Conflict of Interest}

The author(s) confirm that this article content has no conflict of interest.

\section{References}

1. Liebig CW, Congeni JA. Sports-related traumatic brain injury (concussion). Nelson Textbook of Pediatrics. 20th ed. Philadelphia, PA: Elsevier. 2016:688.
2. Gururaj G. Epidemiology of traumatic brain injuries: Indian scenario. Neurological research. 2002; 1; 24 (1):24-8.

3. Marshall LF. Head injury: recent past, present, and future. Neurosurgery. 2000;47(3):546-61.

4. Snell DL, Siegert RJ, Hay-Smith EJ, et al. An examination of the factor structure of the revised illness perception questionnaire modified for adults with mild traumatic brain injury. Brain Injury. 2010 Oct 24 (13-14):1595-1605.

5. Torbic H, Forni AA, Anger KE, Degrado JR, Greenwood BC. Use of antiepileptics for seizure prophylaxis after traumatic brain injury. Am J Health Syst Pharm 2013;70:759-66.

6. Lucke-Wold BP, Nguyen L, Turner RC, Logsdon AF, Chen YW, Smith KE, et al. Traumatic brain injury and epilepsy: Underlying mechanisms leading to seizure. Seizure 2015;33:13-23.

7. Wu MF, Lim WH. Phenytoin: A guide to therapeutic drug monitoring. Proc Singapore Healthc 2013;22:198-202

8. Srisaeng K, Kanjanasilp J, Sriphong $\mathrm{P}$, Kittivaravach C, Wongsrikaew P, Nopsiri W. Population pharmacokinetics of phenytoin in patients with traumatic brain injury. CMU J Nat Sci 2015; 14:231-43.

9. Kalsotra A, Turman CM, Dash PK, Strobel HW. Differential effects of traumatic brain injury on the cytochrome $\mathrm{p} 450$ system: A perspective into hepatic and renal drug metabolism. J Neurotrauma 2003; 20:1339-50.

10. Pokorna P, Wildschut ED, Vobruba V, van den Anker JN, Tibboel D. The impact of hypothermia on the pharmacokinetics of drugs used in neonates and young infants. Curr Pharm Des 2015; 21:5705-24.

11. Cwik MJ, Liang M, Deyo K, Andrews C, Fischer J. Simultaneous rapid high-performance liquid chromatographic determination of phenytoin and its prodrug, fosphenytoin in human plasma and ultrafiltrate. J Chromatogr B Biomed Sci Appl 1997;693:407-14

12. Griebel ML, Kearns GL, Fiser DH, Woody RC, Turley CP. Phenytoin protein binding in pediatric patients with acute traumatic injury. Crit Care Med 1990;18:385-91.

13. Boucher BA, Rodman JH, Fabian TC, Cupit GC, Ludden TM, West $\mathrm{ME}$, et al. Disposition of phenytoin in critically ill trauma patients. Clin Pharm 1987;6:881-7.

14. Boucher BA, Rodman JH, Jaresko GS, Rasmussen SN, Watridge CB, Fabian TC, et al. Phenytoin pharmacokinetics in critically ill trauma patients. Clin Pharmacol Ther 1988;44:675-83.

15. Markowsky SJ, Skaar DJ, Christie JM, Eyer SD, Ehresman DJ. Phenytoin protein binding and dosage requirements during acute and convalescent phases following brain injury. Ann Pharmacother 1996;30:443-8.

16. Bauer LA, Edwards WA, Dellinger EP, Raisys VA, Brennan C. Importance of unbound phenytoin serum levels in head trauma patients. J Trauma 1983;23:1058-60.

17. Sadeghi K, Hadi F, Ahmadi A, Hamishehkar H, Beigmohammadi MT, Mahmoodpoor A, et al. Total phenytoin concentration is not well correlated with active free drug in critically-ill head trauma patients. J Res Pharm Pract 2013;2:105-9.

18. Boucher BA, Hanes SD. Pharmacokinetic alterations after severe head injury. Clinical relevance. Clin Pharmacokinet 1998;35:209-21.

19. Boucher BA, Wood GC, Swanson JM. Pharmacokinetic changes in critical illness. Crit Care Clin 2006; 22:255-71. 